\title{
Requalification of a Brazilian Trichoderma Collection and Screening of Its Capability to Decolourise Real Textile Effluent
}

\author{
Dianny Silva Lisboa ${ }^{1}$, Cledir Santos ${ }^{2, *}$, Renan N. Barbosa ${ }^{1}$, Oliane Magalhães ${ }^{1}$, \\ Laura M. Paiva ${ }^{1}$, Keila A. Moreira ${ }^{3}$, Nelson Lima ${ }^{4}$ and Cristina M. Souza-Motta ${ }^{1}$ \\ 1 Department of Mycology, Centre of Biological Sciences, Federal University of Pernambuco, Recife, \\ PE 50740-600, Brazil; dy_carol@hotmail.com (D.S.L.); renan.rnb@gmail.com (R.N.B.); \\ olimicomed@yahoo.com.br (O.M.); mesquitapaiva@terra.com.br (L.M.P); cristina.motta@ufpe.br (C.M.S.-M.) \\ 2 Department of Chemical Sciences and Natural Resources, Centro de Excelencia en Investigación \\ Biotecnológica Aplicada al Medio Ambiente (CIBAMA), Scientific and Technological Bioresource \\ Nucleus (BIOREN), Universidad de La Frontera, Temuco 4811-230, Chile \\ 3 Academic Unity of Garanhuns, Federal Rural University of Pernambuco, Garanhuns, PE 55292-270, Brazil; \\ moreiralab@yahoo.com.br \\ 4 CEB-Centre of Biological Engineering, Micoteca da Universidade do Minho, University of Minho, \\ Braga 4710-057, Portugal; nelson@ie.uminho.pt \\ * Correspondence: cledir.santos@ufrontera.cl; Tel.: +56-452-596-726; Fax: +56-452-325-440 \\ Academic Editor: Jason K. Levy
}

Received: 27 January 2017; Accepted: 27 March 2017; Published: 1 April 2017

\begin{abstract}
Water contamination with large amounts of industrial textile coloured effluents is an environmental concern. For the treatment of textile effluents, white-rot fungi have received extensive attention due to their powerful capability to produce oxidative (e.g., ligninolytic) enzymes. In addition, other groups of fungi, such as species of Aspergillus and Trichoderma, have also been used for textile effluents treatment. The main aim of the present study was to requalify a Brazilian Trichoderma culture collection of 51 Trichoderma strains, isolated from different sources in Brazil and preserved in the oldest Latin-American Fungal Service Culture Collection, The Micoteca URM WDCM 804 (Recife, Brazil). Fungal isolates were re-identified through a polyphasic approach including macro- and micro-morphology and molecular biology, and screened for their capability to decolourise real effluents collected directly from storage tanks of a textile manufacture. Trichoderma atroviride URM 4950 presented the best performance on the dye decolourisation in real textile effluent and can be considered in a scale-up process at industrial level. Overall, the potential of Trichoderma strains in decolourising real textile dye present in textile effluent and the production of the oxidative enzymes $\mathrm{Lac}, \mathrm{LiP}$ and $\mathrm{MnP}$ was demonstrated. Fungal strains are available in the collection e-catalogue to be further explored from the biotechnological point of view.
\end{abstract}

Keywords: culture collection; filamentous fungi; laccase; lignin peroxidase; manganese peroxidase; textile effluent decolourisation; Trichoderma identification

\section{Introduction}

Textile industries waste large water quantities that in some cases return to environment as untreated or incorrectly treated effluents [1]. Due to the presence of non-fixed dyes during the dyeing process, these wastewaters are highly coloured $[2,3]$. Water contamination with large amounts of coloured effluents is a serious environmental problem.

There are mainly three types of treatment for textile effluents: physical, chemical and biological. In recent years, relevant methods based on biological textile effluents degradation have been developed 
using bacteria and fungi in aerobic and anaerobic processes [1,2,4-10]. A recent review on current technologies for biological treatment of textile wastewater discusses in deep these bioprocesses [11]. The use of oxidative enzymes, mainly Lac and peroxidases, in textile industry has increased quickly. It has been due to both: (a) the ability of these oxidative enzymes to bleach textiles; and (b) the biological treatments involving these enzymes seem to be an attractive solution mainly because most existing treatments (e.g., coagulation/flocculation, adsorption, ion exchange, and electrochemical methods) of dye wastewater utilize ineffective and uneconomical processes [12]. In addition, other biomimetic oxidative bleaches, like metalloporphyrins, are very promising catalysts for synthetic textile dyes. However, they also show some limitations and drawbacks [13].

For the treatment of textile effluents, white-rot fungi have been extensive assessed due to their powerful capability to produce oxidative, including ligninolytic (e.g., laccase (Lac), lignin peroxidase $(\mathrm{LiP})$ and manganese peroxidase $(\mathrm{MnP})$ ) enzymes [6]. Other groups of fungi have also been evaluated for textile effluents treatment (e.g., species of ascomycetes like Aspergillus and Trichoderma) [6,11]. In addition, although the oxidative system is frequently produced during fungal secondary metabolism, different microorganisms produce different enzymes depending on cultivation conditions [4-6,14].

Trichoderma is a very genetically diverse genus with interesting features, which make some of its species of agricultural and industrial interest. Species of Trichoderma are widely used in the production of enzymes for both pulp treatment and food production [15]. In addition, there are also different reports showing the potential of these fungi to remediate the pollution of soil and water [14,16-18].

All these features make Trichoderma an important fungal taxonomic group for biotechnological application. As a matter of consequence, for microbial culture collections that have Trichoderma in their catalogues it is important to have these assets identified and characterised according to the current state-of-the-art. Considering this, the main aim of the present study was to requalify a Brazilian Trichoderma culture collection of 51 Trichoderma strains, isolated from different sources in Brazil and preserved in the oldest Latin-American Fungal Service Culture Collection, The Micoteca URM WDCM 804 (Recife, Brazil). The requalification work was based on the fungal identification through a polyphasic approach including macro- and micro-morphology, molecular biology and screening their capability to decolourise real effluents collected directly from storage tanks of a textile manufacture.

\section{Materials and Methods}

\subsection{Microorganisms and Culture Conditions}

Fifty-one Trichoderma strains previously isolated from different substrates of geographic regions of Brazil (see Table 1) were obtained from the Fungal Culture Collection Micoteca URM (Department of Mycology, Federal University of Pernambuco-UFPE, Recife, Brazil, www.ufpe.br/micoteca). The Micoteca URM is a culture collection registered at the World Federation for Culture Collections (WFCC) under the number WDCM 604 and certified in the ISO 9001:2015 standard under the Certificate Number BR018207-1. Fungal strains were obtained from preserved form under mineral oil, revived according to the instructions issued by the Micoteca URM culture collection, and grown and maintained in Potato Dextrose Agar plates (PDA, for $1 \mathrm{~L}$ water: $4 \mathrm{~g}$ potato starch, $20 \mathrm{~g}$ dextrose and $15 \mathrm{~g}$ agar).

\subsection{Morphological Fungal Identification}

In order to confirm the taxonomical identification of the 51 Trichoderma strains, macro- and micro-morphological analyses were performed (see Table 1). For macro-morphological analyses, the strains were grown on PDA plates at 30,35 and $40{ }^{\circ} \mathrm{C}$, and on Synthetic Low-Nutrient Agar plates (SNA, for $1 \mathrm{~L}$ water: $1.0 \mathrm{~g} \mathrm{KH}_{2} \mathrm{PO}_{4}, 1.0 \mathrm{~g} \mathrm{KNO}, 0.5 \mathrm{~g} \mathrm{MgSO}_{4} \cdot 7 \mathrm{H}_{2} \mathrm{O}, 0.5 \mathrm{~g} \mathrm{KCl}, 0.2 \mathrm{~g}$ glucose, $0.2 \mathrm{~g}$ sucrose and $20 \mathrm{~g}$ agar) at $35^{\circ} \mathrm{C}$, in the dark without humidity control and under aerobic conditions.

For micro-morphological analysis, strains were inoculated on Cornmeal Agar Medium supplemented with dextrose plates (CMD, for $1 \mathrm{~L}$ water: $30 \mathrm{~g}$ cornmeal, $20 \mathrm{~g}$ dextrose and $20 \mathrm{~g}$ agar). Fungi were incubated at $25^{\circ} \mathrm{C}$ for 3 days in the same conditions described above. Afterwards, 
$6 \mathrm{~mm}$ diameter plugs of each CMD fungal culture were inoculated on PDA plates and grown for 4 days in the same conditions but with a regime of 12:12 h light:dark.

Conidia and phialides, presence of chlamydospores and sterile hyphae were observed using $90 \%$ lactic acid slides on a light microscopy. Final morphological identification followed the taxonomic keys and guides available for Trichoderma $[19,20]$.

\subsection{Molecular Fungal Identification}

For the molecular identification, the fungal strains were cultivated in Minimum Liquid Medium (MLM, for $1 \mathrm{~L}$ water: $10 \mathrm{~g}$ glucose, $10 \mathrm{~g} \mathrm{KH}_{2} \mathrm{PO}_{4} ; 6 \mathrm{~g}\left(\mathrm{NH}_{4}\right)_{2} \mathrm{SO}_{4}, 1 \mathrm{~g} \mathrm{MgSO}_{4} \cdot 7 \mathrm{H}_{2} \mathrm{O}, 5 \mathrm{mg} \mathrm{FeSO}{ }_{4} \cdot 7 \mathrm{H}_{2} \mathrm{O}$, $1.6 \mathrm{mg} \mathrm{MnSO}_{4} \cdot \mathrm{H}_{2} \mathrm{O}, 1.4 \mathrm{mg} \mathrm{ZnSO}{ }_{4} \cdot 7 \mathrm{H}_{2} \mathrm{O}$ and, $\left.2 \mathrm{mg} \mathrm{CaC1} 1_{2} \cdot 2 \mathrm{H}_{2} \mathrm{O}\right)$ at $28{ }^{\circ} \mathrm{C}$ under static condition for $96 \mathrm{~h}$. Mycelia were filtered and collected for extraction of genomic DNA according to the method previously described elsewhere [21]. Amplifications of gene regions ITS1-5.8S-ITS2 and translation elongation factor 1-alpha (tef1) were performed in $50 \mu \mathrm{L}$ mixture containing: buffer Taq DNA polymerase $1 \times ; 1.5 \mathrm{mM}$ of $\mathrm{MgCl}_{2} ; 0.4 \mu \mathrm{M}$ each primer (ITS1: 5'-TCCGTAGGTGAACCTGCGG-3'; ITS4: 5'-TCCTCCGCTTATTGATATGC-3'; EF1-728F: 5'-CATCGAGAAGTTCGAGAAGG-3'; TEF1 rev: 5'-GCCATCCTTGGAGATACCAGC-3') [22-24]; $0.2 \mathrm{mM}$ of dNTPs; $0.2 \mathrm{U}$ of Taq DNA polymerase; and 25 ng of DNA template.

The thermal cycling parameters consisted of initial denaturation at $94{ }^{\circ} \mathrm{C}$ for $2 \mathrm{~min}$ followed by 30 cycles of denaturation at $94{ }^{\circ} \mathrm{C}$ for $30 \mathrm{~s}$, primer annealing at $55^{\circ} \mathrm{C}$ for $30 \mathrm{~s}$, primer extension at $72{ }^{\circ} \mathrm{C}$ for $1 \mathrm{~min}$ and a final extension for $10 \mathrm{~min}$ at $72{ }^{\circ} \mathrm{C}$ [20,21]. Amplification products were visualised on $1 \%$ agarose gel electrophoresis, stained with $0.5 \mu \mathrm{g} / \mathrm{mL}$ of GelGreen ${ }^{\mathrm{TM}}$ under UV light and then photographed and purified using Fermentas ${ }^{\circledR}$ kit (Cambridge, UK). The amplified DNA fragments were sequenced in the Sequencing Platform of the Central Laboratory of the Centre of Biological Sciences, Federal University of Pernambuco, Recife, Brazil.

Electropherograms were analysed and edited in the software Staden Package 2.0. Sequences obtained were used to search the most similar sequences deposited in the GenBank by using the Basic Local Alignment Search Tool (BLAST). The experimental sequences of ITS1-5.8S-ITS2 and tef1 gene regions were aligned and edited together with the retrieved from the database using the software MEGA 5.0. The phylogenetic tree was constructed using the Neighbour Joining method and the Maximum Parsimony (MP), with 1000 bootstrap resampling using the software MEGA 5.0 [25].

\subsection{Decolourisation Assay}

Samples of textile effluent were collected directly from storage tanks in a textile manufacture at the municipality of Toritama, State of Pernambuco, Brazil. The effluent samples were kept at $4{ }^{\circ} \mathrm{C}$ and transferred to the Laboratory of Environmental and Quality Engineering (Department of Chemical Engineering, Federal University of Pernambuco, Recife, Brazil) to perform the physical-chemical analyses and decolourisation assay.

The physical-chemical analyses involved the Chemical Oxygen Demand (COD) by colorimetric method, Biochemical Oxygen Demand (BOD) by azide modification of a Winkler titration method, Colour (HAZEN scale), Turbidity (NTU scale), $\mathrm{pH}$ using the potentiometric measurement principle, and Sedimentable Solids (SD) by gravimetric through a $0.45 \mu \mathrm{m}$ filter membrane, using the standard methods for the examination of water and wastewater [26].

The screening of textile dye decolourisation by Trichoderma strains was assessed by using $6 \mathrm{~mm}$ diameter plugs of fungal cultures previously grown at $30{ }^{\circ} \mathrm{C}$ for 7 days on PDA plates. Plugs were transferred to $125 \mathrm{~mL}$ Erlenmeyer flasks containing $30 \mathrm{~mL}$ of Malt Broth (MB, for $1 \mathrm{~L}$ water: $20 \mathrm{~g}$ malt extract, $1 \mathrm{~g}$ peptone and $20 \mathrm{~g}$ dextrose) supplemented with $1.9 \times 10^{-2} \mathrm{mM}$ Indigo Carmine dye (Sigma-Aldrich, St. Louis, MO, USA).

Fungal cultures were incubated in the dark at $28^{\circ} \mathrm{C}$ for 8 days. Fungal biomass was then removed by filtration through a $0.45 \mu \mathrm{m}$ Millipore membrane and absorbance of filtrates was assessed in a Hitachi U-5100 spectrophotometer at $650 \mathrm{~nm}$ which is the maximum absorption of Indigo Carmine 
$\left(\varepsilon_{650 \mathrm{~nm}}=3.1 \times 10^{3} \mathrm{M}^{-1} \cdot \mathrm{cm}^{-1}\right)$. The Indigo Carmine was used as standard and MB free of inoculum containing dye was used as abiotic control. The decolourisation percentage of Indigo Carmine dye was calculated according to Miranda et al. [27].

Previous to evaluate the decolourisation of the dye present on the real textile effluent, this was sterilised by autoclave at $121^{\circ} \mathrm{C}$ during $15 \mathrm{~min}$. Three different experiments were performed. In each case, 3 plugs of $6 \mathrm{~mm}$ diameter of fungal cultures grown for 7 days at $30^{\circ} \mathrm{C}$ on PDA plates were added to $125 \mathrm{~mL}$ Erlenmeyer flasks containing $30 \mathrm{~mL}$ of: (1) textile effluent; (2) textile effluent supplemented with $0.5 \%(w / v)$ wheat bran, and (3) textile effluent supplemented with $0.05 \%(w / v)$ extract yeast. Cultures were incubated under static conditions, in the dark at $28^{\circ} \mathrm{C}$ for 8 days. Afterwards, $2 \mathrm{~mL}$ aliquots were transferred into tubes and centrifuged at $1035 \mathrm{~g}$ for $15 \mathrm{~min}$ at $4{ }^{\circ} \mathrm{C}$. Supernatants were analysed at $650 \mathrm{~nm}$ in a Hitachi U-5100 spectrophotometer.

The decolourisation results were submitted to analysis of variance and means compared by Friedman test at $5 \%$ probability in the ASSISTAT software [28].

\subsection{Determination of Enzymatic Activities}

In order to determine the activity of $\mathrm{Lac}, \mathrm{LiP}$ and $\mathrm{MnP}, 6 \mathrm{~mm}$ diameter plugs of fungal cultures previously grown for 7 days at $30{ }^{\circ} \mathrm{C}$ on PDA plates were transferred into $125 \mathrm{~mL}$ Erlenmeyer flasks containing $50 \mathrm{~mL}$ of Basal Culture Medium (BCM, for $1 \mathrm{~L}$ water: $0.1 \mathrm{~g}$ glucose; $0.15 \mathrm{~g}$ yeast extract; $4.5 \mathrm{~g}$ wheat bran; and $0.05 \mathrm{~g} \mathrm{NH}_{4} \mathrm{Cl}, \mathrm{pH}$ 6.0). Fungal incubation occurred under static condition in the dark, at $28^{\circ} \mathrm{C}$ for 8 days. The biomass was then separated by filtration through a $0.45 \mu \mathrm{m}$ Millipore membrane. In order to determine the activity of each enzyme, absorbance of filtrates was assessed in a spectrophotometer Hitachi U-5100 and one unit (U) of enzyme was defined as the release of $1.0 \mu \mathrm{mol}$ product formed per min under the assay conditions.

Lac activity was measured from the oxidation of 2,2'-azino-bis(3-ethylbenzothiazoline-6-sulphonic acid) (ABTS). For this reaction, a mixture containing $0.8 \mathrm{~mL}$ ABTS $(0.03 \% v / v), 0.1 \mathrm{~mL}$ sodium acetate buffer (0.1M, pH 5.0) and $0.1 \mathrm{~mL}$ enzymatic extract was used [6]. The oxidation of ABTS was determined at $420 \mathrm{~nm}$ with $\varepsilon_{420 \mathrm{~nm}}=3.6 \times 10^{4} \mathrm{M}^{-1} \cdot \mathrm{cm}^{-1}$. LiP activity was assessed through the oxidation of veratryl alcohol. For this reaction, a mixture containing $1 \mathrm{~mL}$ sodium tartrate buffer solution (125 mM, pH 3.0), $500 \mu \mathrm{L}$ veratryl alcohol $(10 \mathrm{mM}), 500 \mu \mathrm{L}$ hydrogen peroxide $(2 \mathrm{mM})$ and $500 \mu \mathrm{L}$ enzymatic extract was used. The reaction was started by adding hydrogen peroxide to the mixture and the production of veratraldehyde was determined at $310 \mathrm{~nm}$ [29] with $\varepsilon_{310 \mathrm{~nm}}=9.3 \times 10^{3} \mathrm{M}^{-1} \cdot \mathrm{cm}^{-1}$.

MnP activity was assessed by using the methodology of phenol red oxidation measurement as previously described elsewhere [30]. Briefly, the reaction mixture was composed of $500 \mu \mathrm{L}$ enzymatic extract, $100 \mu \mathrm{L}$ phenol red, $100 \mu \mathrm{L}$ sodium lactate $(250 \mathrm{mM}), 200 \mu \mathrm{L}$ bovine albumin $(0.5 \% w / v), 50 \mu \mathrm{L}$ sulphate manganese $(2 \mathrm{mM}), 50 \mu \mathrm{L}$ hydrogen peroxide $(2 \mathrm{mM})$ and $1.0 \mathrm{~mL}$ sodium succinate buffer $\left(20 \mathrm{mM}, \mathrm{pH}\right.$ 4.0). The reactions were performed at $30^{\circ} \mathrm{C}$ for 5 minutes and were stopped by adding $2 \mathrm{~N} \mathrm{NaOH}(40 \mu \mathrm{L})$. MnP activity were determined at $610 \mathrm{~nm}$ with $\varepsilon_{610} \mathrm{~nm}=2.2 \times 10^{3} \mathrm{M}^{-1} \cdot \mathrm{cm}^{-1}$.

Overall, the enzymatic results were submitted to analysis of variance and means compared by Tukey test at $5 \%$ probability in the ASSISTAT software [28].

\subsection{Phenotype Data Analysis}

A cluster analysis was applied and a dendrogram of phenotype relatedness was constructed. The analysis was performed using the phenotype traits that showed at least high association with each Trichoderma species, such as: conidia shape, ornamentation, colour, length and width, and phialide length and base width, and presence of sterile hyphae and chlamydospore, and colony diameter on PDA at 30,35 and $40^{\circ} \mathrm{C}$ and SNA at $35^{\circ} \mathrm{C}$. The analysis was made using the hierarchical clustering with the complete linkage method and was performed with the statistical package jmp 8.0.2 for Macintosh (SAS Institute Inc., Cary, NC, USA). 


\section{Results and Discussion}

\subsection{Morphological and Molecular Identification}

Fifty-one fungal strains obtained from the Micoteca URM culture collection and belonging to the genus Trichoderma were evaluated. Data obtained from the morphological analysis (Table 1 and Figure 1) show a clear difficulty to cluster the strains by morphological traits when a cluster analysis was used. It is well known that, due to homoplasy (i.e., convergent evolution that creates analogous traits with similar form but were not present in the last common ancestor) of morphological characters, it is often impossible to discriminate species of Trichoderma. Notwithstanding this, for other fungal taxonomic groups, the statistical grouping of phenotype traits such as conidia shape, ornamentation and dimensions (length and wide) are normally very good data for species identification when combined with other traits [31,32].

It is well known that the overall range of variation in conidial dimensions in Trichoderma is not great. However, related species can often be differentiated by slight but consistent differences in size. The conidial surface appears smooth in most species in light microscope observations, although many species with apparently smooth-appearing conidia are delicately ornamented when examined by SEM. In most species, terminal phialides tend to be more elongate and narrower, and frequently more or less subulate. Chlamydospores are common in many species, although they tend to be uniformly globose or ellipsoidal, terminal and intercalary, smooth-walled, colourless, yellowish or greenish, and 6-15 um diameter in most species. Vegetative hyphae show few characters useful for identification.

This means that the identification based on the classical morphology techniques can be used as presumptive approach. However, to obtain a sound and reliable identification, molecular biology must be performed [33]. Consequently, in the present study the taxonomic information was revised throughout molecular biology analysis based on the 500 and 600 base pairs fragments obtained from the ITS1-5.8S-ITS2 rDNA and tef1 gene regions, respectively.

Through the phylogenetic analysis based on ITS region, inaccurate clades were observed and the groupings observed for some Trichoderma species were unclear (Figure 2). For instance, for cryptic species like T. aspereloides and T. asperelum, the ITS region was not discriminatory enough. In contrast, through the tef1 gene analysis the species T. aspereloides and T. asperelum were well-delineated. In fact, in Figure 3, it is possible to observe six clades supported with bootstrap above 85\%: Viride (Trichoderma koningiopsis, T. erinaceum and T. atroviride), Hamatum (Trichoderma asperellum, T. asperelloides and T. hamatum); Longibrachiatum (Trichoderma longibrachiatum and T. ghanense); Lone lineages (Trichoderma spirale), Virens (Hypocrea virens/Trichoderma virens), and Harzianum (Hypocrea lixii/ Trichoderma harzianum).

Based on the former identification available in the records of the Micoteca URM culture collection, the 51 fungal isolates were distributed into six Trichoderma species, as shown in the Table 2. Based on the molecular biology analysis presented herein, it was possible to separate them into 11 different species: Trichoderma asperelloides (8 strains), T. asperellum (4), T. atroviride (6), T. erinaceum (3), T. ghanense (1), T. hamatum (4), T. harzianum (13), T. koningiopsis (4), T. longibrachiatum (1), T. spirale (1) and T. virens (6) (Table 2). Overall, only 10 out of 51 (ca. 20\%) isolates retained their former identification, namely, T. hamatum (URM 3492), T. harzianum (URM 4475, 5482, 4720, 6266 and 4328) and T. virens (URM 4358, 3934, 3343 and 6656). 
Table 1. Morphological traits of 51 Trichoderma strains from Micoteca URM culture collection.

\begin{tabular}{|c|c|c|c|c|c|c|c|c|c|c|c|c|c|}
\hline \multirow[b]{2}{*}{ URM } & \multicolumn{5}{|c|}{ Conidia } & \multicolumn{2}{|c|}{ Phialide } & \multirow[b]{2}{*}{ Sterile Hyphae } & \multirow[b]{2}{*}{ Chlamyd. } & \multicolumn{3}{|c|}{ PDA (mm) } & \multirow{2}{*}{$\begin{array}{c}\text { SNA (mm) } \\
35^{\circ} \mathrm{C}\end{array}$} \\
\hline & Shape ${ }^{1}$ & Ornament $^{2}$ & Colour $^{3}$ & $\begin{array}{c}\text { Length } \\
(\mu \mathrm{m})\end{array}$ & $\begin{array}{l}\text { Width } \\
(\mu \mathrm{m})\end{array}$ & $\begin{array}{c}\text { Length } \\
(\mu \mathrm{m})\end{array}$ & $\begin{array}{l}\text { Base Width } \\
\quad(\mu \mathrm{m})\end{array}$ & & & $30^{\circ} \mathrm{C}$ & $35^{\circ} \mathrm{C}$ & $40^{\circ} \mathrm{C}$ & \\
\hline 3280 & GL/SGL & SW & G & $2.8-3.4$ & $2.2-2.7$ & $10.2-11.9$ & $1.8-2.0$ & - & + & 67.0 & 9.0 & $\varnothing$ & 7.0 \\
\hline 6239 & GL/SGL & SW & G & $2.8-3.4$ & $3.2-3.6$ & $8.5-10.2$ & $1.8-2.0$ & - & - & 77.0 & 24.0 & $\varnothing$ & 16.0 \\
\hline 3086 & GL/SGL & SW & G & $2.8-3.4$ & $2.2-2.7$ & $10.2-11.9$ & $1.8-2.0$ & - & + & 51.0 & 31.0 & $\varnothing$ & 23.0 \\
\hline 3487 & GL/SGL & SW & G & $2.8-3.4$ & $2.2-2.7$ & $10.2-11.9$ & $1.8-2.0$ & - & + & 74.0 & 28.0 & $\varnothing$ & 24.0 \\
\hline 3271 & GL/SGL & SW & G & $2.8-3.4$ & $3.2-3.6$ & $8.5-10.2$ & $1.8-2.0$ & - & - & 65.0 & 26.0 & $\varnothing$ & 15.0 \\
\hline 5007 & SGL/O & SW & G & $2.8-3.4$ & $2.7-3.2$ & $8.5-10.2$ & $2.0-2.6$ & - & - & 78.0 & 44.0 & $\varnothing$ & 23.0 \\
\hline 4358 & GL/SGL & SW & G & $3.5-4.1$ & $2.2-2.7$ & $10.2-11.9$ & $1.8-2.0$ & - & + & 76.0 & 25.0 & $\varnothing$ & 20.0 \\
\hline 3934 & GL/SGL & SW & G & $3.5-4.1$ & $2.2-2.7$ & $10.2-11.9$ & $1.8-2.0$ & - & + & 75.0 & 23.0 & $\varnothing$ & 21.0 \\
\hline 3343 & GL/SGL & SW & G & $2.8-3.4$ & $2.2-2.7$ & $8.5-10.2$ & $2.0-2.6$ & - & - & 73.0 & 14.0 & $\varnothing$ & 6.0 \\
\hline 6656 & SGL/O & SW & G & $2.8-3.4$ & $2.2-2.7$ & $8.5-10.2$ & $2.0-2.6$ & - & + & 77.0 & 22.0 & $\varnothing$ & 18.0 \\
\hline 4926 & GL/SGL & SW & G & $2.8-3.4$ & $3.2-3.6$ & $8.5-10.2$ & $1.8-2.0$ & + & + & 71.0 & 32.0 & $\varnothing$ & 27.0 \\
\hline 3197 & SGL/O & SW & G & $2.8-3.4$ & $2.2-2.7$ & $10.2-11.9$ & $2.6-3.1$ & - & + & 52.0 & 24.0 & $\varnothing$ & 18.0 \\
\hline 3735 & GL/SGL & $\mathrm{S}$ & G & $3.5-4.1$ & $2.7-3.2$ & $8.5-10.2$ & $2.6-3.1$ & - & - & 44.0 & $\varnothing$ & $\varnothing$ & $\varnothing$ \\
\hline 3734 & GL/SGL & S & G & $3.5-4.1$ & $2.7-3.2$ & $8.5-10.2$ & $2.6-3.1$ & - & - & 71.0 & $\varnothing$ & $\varnothing$ & $\varnothing$ \\
\hline 6625 & GL/SGL & S & G & $2.8-3.4$ & $2.7-3.2$ & $8.5-10.2$ & $1.8-2.0$ & - & - & 69.0 & $\varnothing$ & $\varnothing$ & $\varnothing$ \\
\hline 4950 & GL/SGL & S & G & $3.5-4.1$ & $2.7-3.2$ & $8.5-10.2$ & $2.6-3.1$ & - & - & 77.0 & $\varnothing$ & $\varnothing$ & $\varnothing$ \\
\hline 3601 & GL/SGL & $\mathrm{S}$ & G & $3.5-4.1$ & $2.7-3.2$ & $8.5-10.2$ & $2.6-3.1$ & - & - & 80.0 & $\varnothing$ & $\varnothing$ & $\varnothing$ \\
\hline 3270 & GL/SGL & S & G & $3.5-4.1$ & $2.7-3.2$ & $8.5-10.2$ & $2.6-3.1$ & - & - & 40.0 & $\varnothing$ & $\varnothing$ & $\varnothing$ \\
\hline 4162 & $\mathrm{E}$ & S & G & $4.2-4.8$ & $2.7-3.2$ & $6.8-8.5$ & $1.8-2.0$ & - & + & 73.0 & 20.0 & $\varnothing$ & 17.0 \\
\hline 4172 & E & $\mathrm{S}$ & G & $4.2-4.8$ & $3.2-3.6$ & $6.8-8.5$ & $1.8-2.0$ & - & + & 46.0 & 9.0 & $\varnothing$ & 8.0 \\
\hline 3881 & E & $\mathrm{S}$ & G & $4.2-4.8$ & $3.2-3.6$ & $6.8-8.5$ & $1.8-2.0$ & - & + & 50.0 & 14.0 & $\varnothing$ & 11.0 \\
\hline 3732 & E & S & G & $4.9-5.5$ & $2.7-3.2$ & $5.1-6.8$ & $2.0-2.6$ & - & - & 75.0 & 75.0 & 56.0 & 77.0 \\
\hline 3341 & SGL/O & S & G & $3.5-4.1$ & $2.7-3.2$ & $10.2-11.9$ & $2.0-2.6$ & + & + & 54.0 & $\varnothing$ & $\varnothing$ & $\varnothing$ \\
\hline 3476 & SGL/O & $\mathrm{S}$ & G & $3.5-4.1$ & $2.7-3.2$ & $10.2-11.9$ & $2.0-2.6$ & + & + & 63.0 & $\varnothing$ & $\varnothing$ & $\varnothing$ \\
\hline 3492 & SGL/O & $\mathrm{S}$ & G & $2.8-3.4$ & $2.7-3.2$ & $10.2-11.9$ & $1.8-2.0$ & + & + & 64.0 & 25.0 & $\varnothing$ & 9.0 \\
\hline 4722 & SGL/O & $\mathrm{S}$ & G & $3.5-4.1$ & $2.7-3.2$ & $10.2-11.9$ & $2.0-2.6$ & + & + & 42.0 & $\varnothing$ & $\varnothing$ & $\varnothing$ \\
\hline 5351 & SGL/O & $\mathrm{S}$ & G & $2.4-2.7$ & $1.8-2.2$ & $8.5-10.2$ & $1.8-2.0$ & + & + & 75.0 & 35.0 & $\varnothing$ & 36.0 \\
\hline 6668 & SGL/O & S & G & $2.8-3.4$ & $2.2-2.7$ & $6.8-8.5$ & $1.8-2.0$ & - & + & 79.0 & 44.0 & $\varnothing$ & 38.0 \\
\hline 3935 & SGL/O & S & G & $2.4-2.7$ & $1.8-2.2$ & $10.2-11.9$ & $2.0-2.6$ & - & - & 58.0 & 20.0 & $\varnothing$ & 14.0 \\
\hline 5574 & SGL/O & $\mathrm{S}$ & G & $2.8-3.4$ & $1.8-2.2$ & $6.8-8.5$ & $1.8-2.0$ & + & - & 65.0 & 7.0 & $\varnothing$ & 6.0 \\
\hline 4463 & SGL/O & S & G & $2.8-3.4$ & $1.8-2.2$ & $8.5-10.2$ & $1.8-2.0$ & - & - & 78.0 & 29.0 & $\varnothing$ & 29.0 \\
\hline 2842 & SGL/O & S & G & $2.8-3.4$ & $2.2-2.7$ & $10.2-11.9$ & $2.0-2.6$ & - & - & 71.0 & 13.0 & $\varnothing$ & 10.0 \\
\hline 6669 & SGL/O & S & G & $2.4-2.7$ & $1.8-2.2$ & $10.2-11.9$ & $2.0-2.6$ & - & - & 58.0 & 17.0 & $\varnothing$ & 12.0 \\
\hline 4475 & SGL/O & $\mathrm{S}$ & G & $2.4-2.7$ & $1.8-2.2$ & $10.2-11.9$ & $2.0-2.6$ & - & - & 68.0 & 17.0 & $\varnothing$ & 13.0 \\
\hline 5482 & SGL/O & $\mathrm{S}$ & G & $2.4-2.7$ & $1.8-2.2$ & $10.2-11.9$ & $2.0-2.6$ & - & - & 57.0 & 31.0 & $\varnothing$ & 28.0 \\
\hline 4720 & GL/SGL & S & G & $2.4-2.7$ & $2.2-2.7$ & $8.5-10.2$ & $2.0-2.6$ & - & - & 64.0 & 15.0 & $\varnothing$ & 11.0 \\
\hline 6266 & SGL/O & S & G & $2.4-2.7$ & $1.8-2.2$ & $5.1-6.8$ & $1.8-2.0$ & - & + & 79.0 & 28.0 & $\varnothing$ & 11.0 \\
\hline 4328 & SGL/O & $\mathrm{S}$ & G & $2.4-2.7$ & $1.8-2.2$ & $10.2-11.9$ & $2.0-2.6$ & - & - & 50.0 & 8.0 & $\varnothing$ & 8.0 \\
\hline
\end{tabular}


Table 1. Cont

\begin{tabular}{|c|c|c|c|c|c|c|c|c|c|c|c|c|c|}
\hline \multirow[b]{2}{*}{ URM } & \multicolumn{5}{|c|}{ Conidia } & \multicolumn{2}{|c|}{ Phialide } & \multirow[b]{2}{*}{ Sterile Hyphae } & \multirow[b]{2}{*}{ Chlamyd. } & \multicolumn{3}{|c|}{ PDA (mm) } & \multirow{2}{*}{$\begin{array}{c}\text { SNA }(\mathrm{mm}) \\
35^{\circ} \mathrm{C}\end{array}$} \\
\hline & Shape $^{1}$ & Ornament $^{2}$ & Colour $^{3}$ & $\begin{array}{c}\text { Length } \\
(\mu \mathrm{m})\end{array}$ & $\begin{array}{l}\text { Width } \\
(\mu \mathrm{m})\end{array}$ & $\begin{array}{l}\text { Length } \\
(\mu \mathrm{m})\end{array}$ & $\begin{array}{l}\text { Base Width } \\
\quad(\mu \mathrm{m})\end{array}$ & & & $30^{\circ} \mathrm{C}$ & $35^{\circ} \mathrm{C}$ & $40^{\circ} \mathrm{C}$ & \\
\hline 2820 & SGL/O & $\mathrm{S}$ & G & $2.8-3.4$ & $1.8-2.2$ & $6.8-8.5$ & $2.0-2.6$ & - & - & 74.0 & 23.0 & $\varnothing$ & 19.0 \\
\hline 3606 & GL/SGL & S & G & $3.5-4.1$ & $2.7-3.2$ & $13.6-15.2$ & $2.0-2.6$ & - & - & 54.0 & 12.0 & $\varnothing$ & 3.0 \\
\hline 4723 & E & S & G & $3.5-4.1$ & $1.8-2.2$ & $6.8-8.5$ & $1.8-2.0$ & - & - & 76.0 & 8.0 & $\varnothing$ & 15.0 \\
\hline 4745 & E & $\mathrm{S}$ & G & $3.5-4.1$ & $1.8-2.2$ & $6.8-8.5$ & $1.8-2.0$ & - & - & 74.0 & 10.0 & $\varnothing$ & 17.0 \\
\hline 3880 & E & S & G & $3.5-4.1$ & $1.8-2.2$ & $6.8-8.5$ & $1.8-2.0$ & - & - & 72.0 & 11.0 & $\varnothing$ & 13.0 \\
\hline 5158 & E & S & G & $3.5-4.1$ & $2.2-2.7$ & $10.2-11.9$ & $2.6-3.1$ & - & + & 83.0 & 83.0 & 31.0 & 80.0 \\
\hline 3276 & OB & $\mathrm{S}$ & G & $3.5-4.1$ & $2.7-3.2$ & $5.1-6.8$ & $2.6-3.1$ & + & + & 67.0 & 9.0 & $\varnothing$ & $\varnothing$ \\
\hline 5629 & SGL/O & $\mathrm{S}$ & G & $3.5-4.1$ & $2.2-2.7$ & $13.6-15.2$ & $1.8-2.0$ & - & + & 56.0 & 28.0 & $\varnothing$ & 27.0 \\
\hline 4210 & SGL/O & $\mathrm{S}$ & G & $3.5-4.1$ & $2.7-3.2$ & $13.6-15.2$ & $2.0-2.6$ & - & - & 82.0 & 27.0 & $\varnothing$ & 24.0 \\
\hline 4466 & GL/SGL & S & G & $3.5-4.1$ & $2.7-3.2$ & $10.2-11.9$ & $2.0-2.6$ & - & + & 53.0 & 21.0 & $\varnothing$ & 20.0 \\
\hline 4951 & GL/SGL & S & G & $3.5-4.1$ & $2.7-3.2$ & $10.2-11.9$ & $2.0-2.6$ & + & + & 66.0 & 43.0 & $\varnothing$ & 16.0 \\
\hline 4996 & GL/SGL & S & G & $4.2-4.8$ & $3.2-3.6$ & $8.5-10.2$ & $2.6-3.1$ & - & + & 69.0 & 35.0 & $\varnothing$ & 25.0 \\
\hline 2596 & SGL/O & S & $\mathrm{W} / \mathrm{Y}$ & $3.5-4.1$ & $2.7-3.2$ & $13.6-15.2$ & $2.6-3.1$ & - & + & 73.0 & 28.0 & $\varnothing$ & 28.0 \\
\hline
\end{tabular}




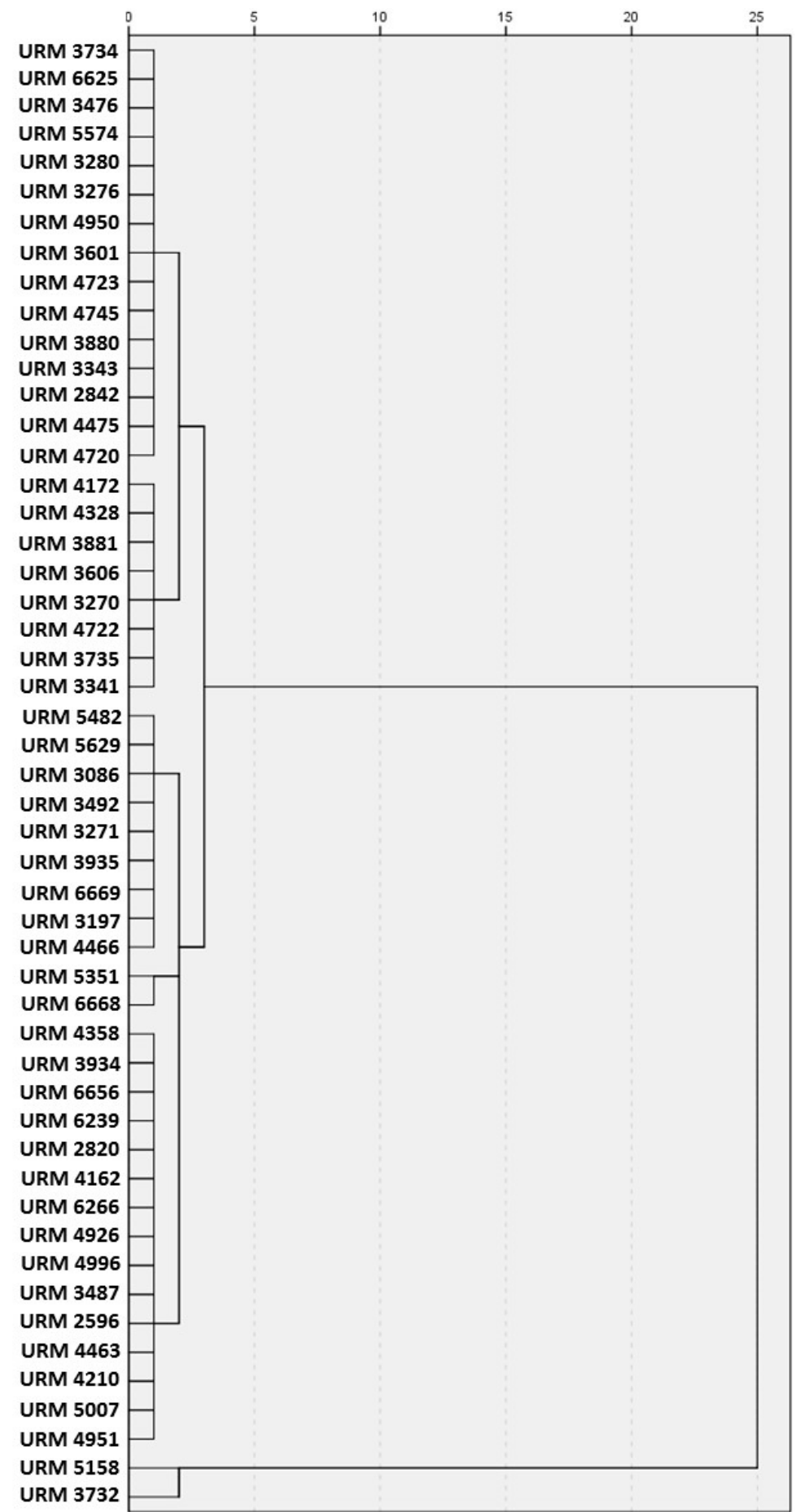

Figure 1. Dendrogram using the hierarchical cluster analysis (average linkage between groups) of relatedness among the strains of Trichoderma based on the morphological analysis data in Table 1. 


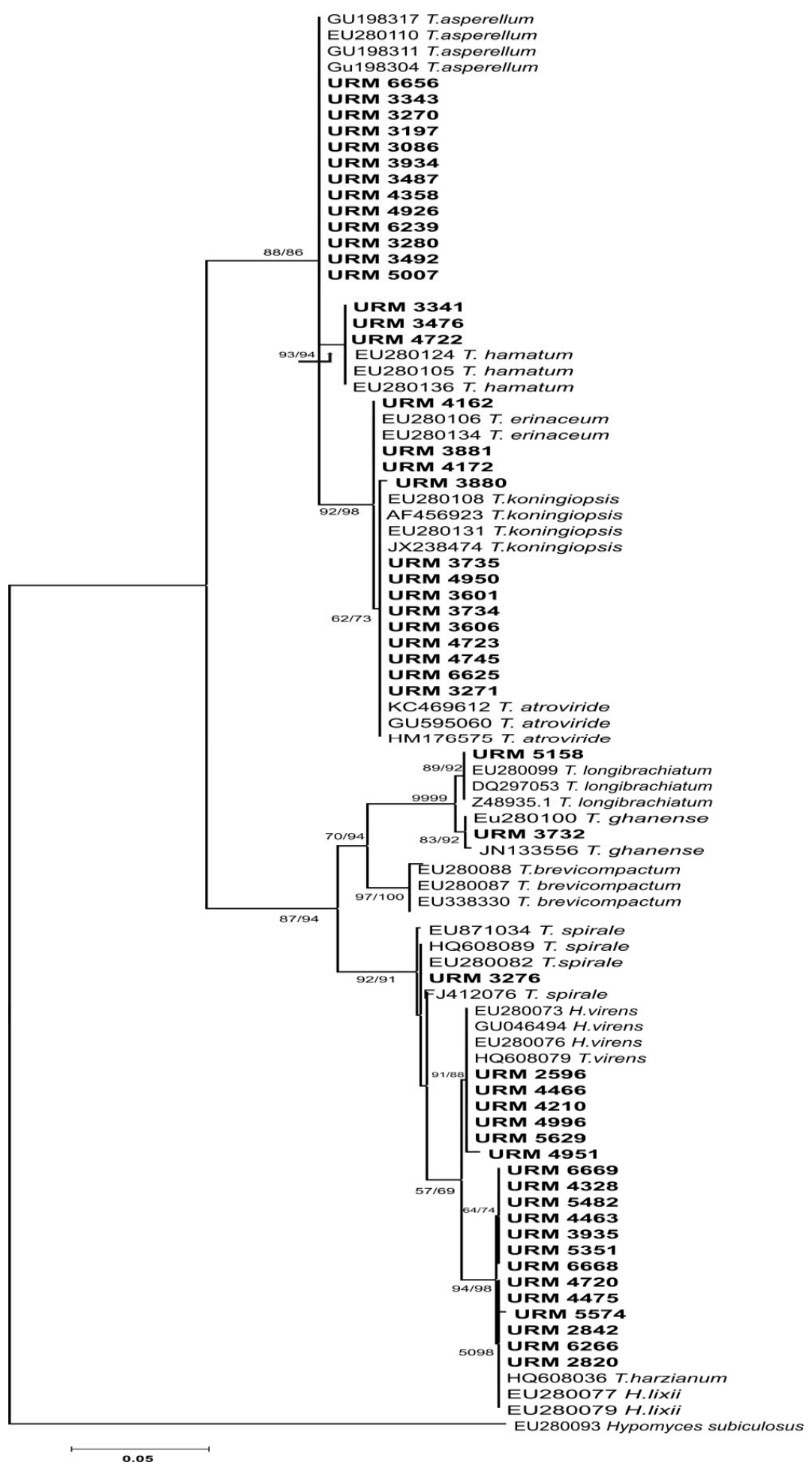

Figure 2. Molecular phylogenetic analysis of ITS1-5.8S-ITS2 for Trichoderma strains by maximum likelihood method. Indicated phylogenetic relationships were inferred with the maximum likelihood method based on the Kimura-2 parameter substitution model and 1000 bootstrap replicates conducted in MEGA5. Only those values with greater than $50 \%$ confidence are shown. Scale bar indicates nucleotide substitutions per site. Hypomyces subiculosus (EU280093 ITS sequence) was used as out group. 


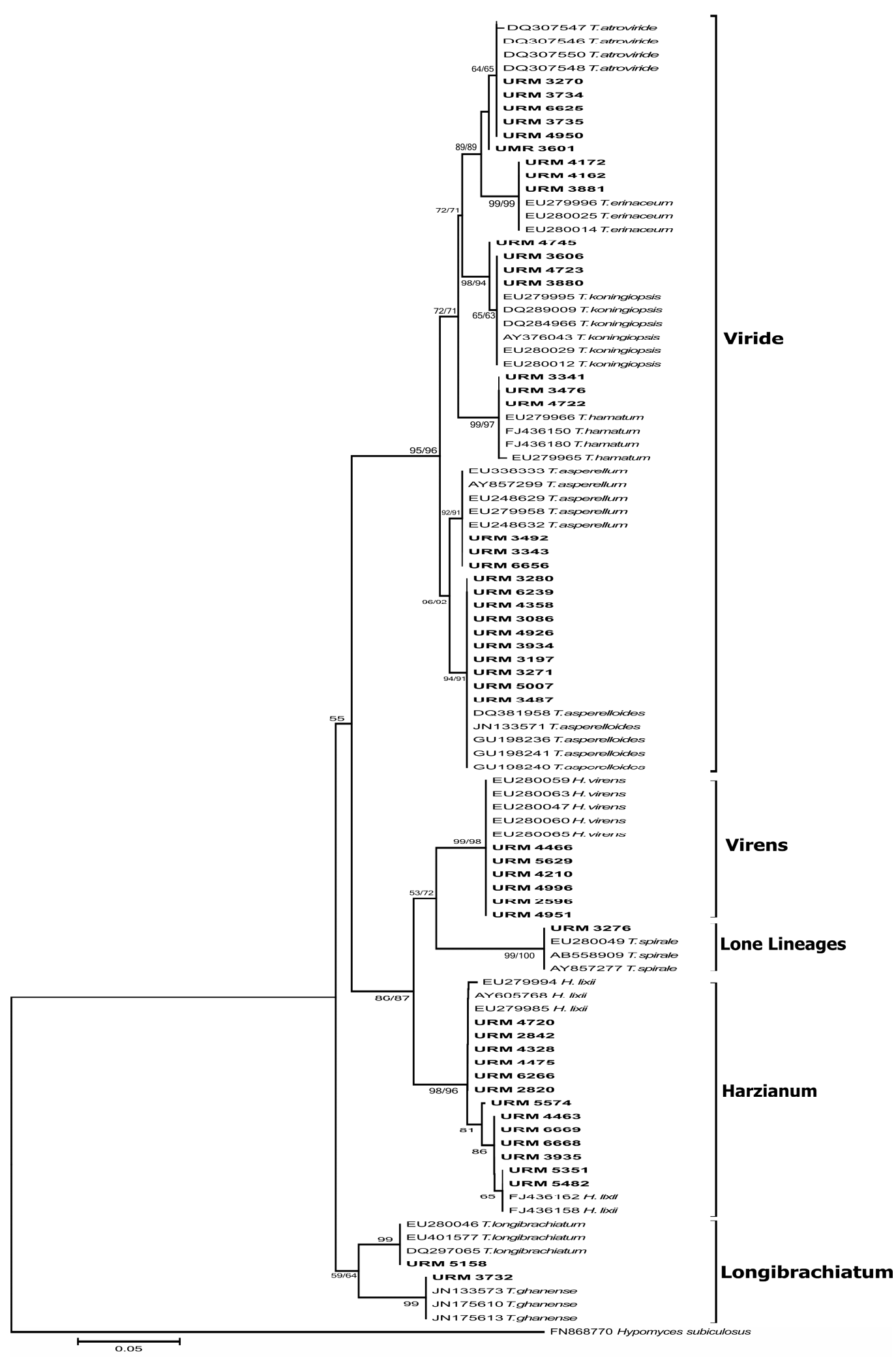

Figure 3. Molecular phylogenetic analysis of tef1 for Trichoderma strains by maximum likelihood method. Indicated phylogenetic relationships were inferred with the maximum likelihood method based on the Kimura-2 parameter substitution model and 1000 bootstrap replicates conducted in MEGA5. Only those values with greater than 50\% confidence are shown. Scale bar indicates nucleotide substitutions per site. Hypomyces subiculosus (FN868770 tef1 sequence) was used as out group. 
Table 2. Re-identification of bio-resources from Micoteca URM culture collections after morphological and molecular characterisation.

\begin{tabular}{|c|c|c|c|c|c|}
\hline URM & $\begin{array}{c}\text { Revised } \\
\text { Identification }\end{array}$ & $\begin{array}{c}\text { Original } \\
\text { Identification }\end{array}$ & $\begin{array}{l}\text { Deposit } \\
\text { Year }\end{array}$ & Substrate & $\begin{array}{c}\text { Geographical } \\
\text { Origin (Brazil) }\end{array}$ \\
\hline 3280 & T. asperelloides & T. harzianum & 1992 & Soil & Paraná \\
\hline 6239 & T. asperelloides & T. harzianum & 2010 & Soil & Pernambuco \\
\hline 3086 & T. asperelloides & T. harzianum & 1989 & Leaf of $R$. gardenioides & São Paulo \\
\hline 3487 & T. asperelloides & T. koningii & 1994 & Birds faeces & Pernambuco \\
\hline 3271 & T. asperelloides & T. koningii & 1992 & Unknown & São Paulo \\
\hline 5007 & T. asperelloides & T. virens & 2005 & Soil & Pernambuco \\
\hline 4358 & T. asperelloides & T. virens & 2001 & Soil & Pernambuco \\
\hline 3934 & T. asperelloides & T. virens & 1997 & Water & Pernambuco \\
\hline 3343 & T. asperellum & T. aureoviride & 1993 & Unknown & Pernambuco \\
\hline 6656 & T. asperellum & T. hamatum & 2012 & Soil with textile effluent & Pernambuco \\
\hline 4926 & T. asperellum & T. harzianum & 2005 & Clay soil & Pernambuco \\
\hline 3197 & T. asperellum & T. harzianum & 1990 & Amazonian nuts & Pará \\
\hline 3735 & T. atroviride & T. aureoviride & 1997 & Lake water & Pernambuco \\
\hline 3734 & T. atroviride & T. aureoviride & 1997 & Lake water & Pernambuco \\
\hline 6625 & T. atroviride & T. aureoviride & 2012 & Soil of agroforestry & Pernambuco \\
\hline 4950 & T. atroviride & T. harzianum & 2005 & Soil & Pernambuco \\
\hline 3601 & T. atroviride & T. harzianum & 1995 & Unknown & Paraná \\
\hline 3270 & T. atroviride & T. harzianum & 1992 & Unknown & São Paulo \\
\hline 4162 & T. erinaceum & T. aureoviride & 1999 & Rhizosphere of sunflower & Pernambuco \\
\hline 4172 & T. erinaceum & T. harzianum & 1999 & Rhizosphere of sunflower & Pernambuco \\
\hline 3881 & T. erinaceum & T. koningii & 1997 & Soil of P. edulis culture & Pernambuco \\
\hline 3732 & T. ghanense & T. koningii & 1997 & Lake water & Pernambuco \\
\hline 3341 & T. hamatum & T. aureoviride & 1992 & Rhizosphere of $V$. herbacea & São Paulo \\
\hline 3476 & T. hamatum & T. aureoviride & 1993 & Rhizosphere of $V$. herbacea & São Paulo \\
\hline 3492 & T. hamatum & T. hamatum & 1994 & Birds faeces & Pernambuco \\
\hline 4722 & T. hamatum & T. harzianum & 2003 & Garden of A. cephalotes & Alagoas \\
\hline 5351 & T. harzianum & T. aureoviride & 2006 & Sugarcane & Unknown \\
\hline 6668 & T. harzianum & T. aureoviride & 2012 & Soil with textile effluent & Pernambuco \\
\hline 3935 & T. harzianum & T. aureoviride & 1997 & River water & Pernambuco \\
\hline 5574 & T. harzianum & T. aureoviride & 2007 & Mangrove sediment & Pernambuco \\
\hline 4463 & T. harzianum & T. aureoviride & 2002 & Sea water & Pernambuco \\
\hline 2842 & T. harzianum & T. aureoviride & 1986 & Unknown & Pernambuco \\
\hline 6669 & T. harzianum & T. aureoviride & 2012 & Soil with textile effluent & Pernambuco \\
\hline 4475 & T. harzianum & T. harzianum & 2002 & Beach sand & Pernambuco \\
\hline 5482 & T. harzianum & T. harzianum & 2007 & Unknown & São Paulo \\
\hline 4720 & T. harzianum & T. harzianum & 2003 & Garden of A. cephalotes & Alagoas \\
\hline 6266 & T. harzianum & T. harzianum & 2010 & Soil of agroforestry & Pernambuco \\
\hline 4328 & T. harzianum & T. harzianum & 2001 & Soil of mining & Bahia \\
\hline 2820 & T. harzianum & T. viride & 1985 & Sugarcane bagasse & Alagoas \\
\hline 3606 & T. koningiopsis & T. hamatum & 1995 & Unknown & Paraná \\
\hline 4723 & T. koningiopsis & T. koningii & 2003 & Garden of A. cephalotes & Alagoas \\
\hline 4745 & T. koningiopsis & T. koningii & 2003 & Garden of A. cephalotes & Alagoas \\
\hline
\end{tabular}


Table 2. Cont

\begin{tabular}{cccccc}
\hline URM & $\begin{array}{c}\text { Revised } \\
\text { Identification }\end{array}$ & $\begin{array}{c}\text { Original } \\
\text { Identification }\end{array}$ & $\begin{array}{c}\text { Deposit } \\
\text { Year }\end{array}$ & Substrate & $\begin{array}{c}\text { Geographical } \\
\text { Origin (Brazil) }\end{array}$ \\
\hline 3880 & T. koningiopsis & T. koningii & 1997 & Soil of P. edulis culture & Pernambuco \\
\hline 5158 & T. longibrachiatum & T. aureoviride & 2005 & Cement & Pernambuco \\
\hline 3276 & T. spirale & T. hamatum & 1991 & sorghum & Pernambuco \\
\hline 5629 & T. virens & T. hamatum & - & Unknown & Paraná \\
\hline 4210 & T. virens & T. virens & 1999 & Rhizosphere of sunflower & Pernambuco \\
\hline 4466 & T. virens & T. virens & 2002 & Sea water & Pernambuco \\
\hline 4951 & T. virens & T. virens & 2005 & Soil & Pernambuco \\
\hline 4996 & T. virens & T. virens & 2005 & Soil & Pernambuco \\
\hline 2596 & T. virens & T. viride & 1980 & Unknown & Pernambuco \\
\hline
\end{tabular}

\subsection{Screening of Indigo Carmine Decolourisation in Malt Broth}

Among the 51 Trichoderma strains assessed for decolourisation of Indigo Carmine in MB, 18 of them presented over $70 \%$ decolourisation, which corresponds to $0.57 \times 10^{-2} \mathrm{mM}$ or less residual dye (Table 3). From these fungal strains, three presented values greater than $90 \%$ decolourisation: T. atroviride URM 3270, URM 3735 and URM 6625, which presented dye decolourisation of $96.86 \%$, $94.61 \%$ and $93.57 \%$, respectively. These results corroborate those previous obtained by Adnan et al. [14] for a strain of T. atroviride isolated from tree bark in a Malaysian forest. In that case, authors obtained similar results with $91.1 \%$ decolourisation for the dye Reactive Black 5.

Table 3. The 18 Trichoderma URM strains that presented decolourisation percentages of Indigo Carmine above $70 \%$ and related oxidase enzyme activities $\left(\mathrm{U} \cdot \mathrm{L}^{-1}\right)$ after eight days of incubation.

\begin{tabular}{ccccc}
\hline Species & URM & Lac & LiP & MnP \\
\hline T. asperelloides & 3280 & $1.7^{\mathrm{aC}}$ & $760.0^{\mathrm{cdA}}$ & $379.3^{\mathrm{defB}}$ \\
T. asperellum & 4926 & $8.3^{\mathrm{aC}}$ & $517.3^{\mathrm{fghA}}$ & $366.0^{\mathrm{defgB}}$ \\
T. atroviride & 3270 & $2.0^{\mathrm{aC}}$ & $758.0^{\mathrm{cdA}}$ & $394.0^{\mathrm{defB}}$ \\
T. atroviride & 3735 & $8.3^{\mathrm{aC}}$ & $1307.0^{\mathrm{aA}}$ & $617.3^{\mathrm{bcB}}$ \\
T. atroviride & 4950 & $2.3^{\mathrm{aB}}$ & $750.0^{\mathrm{cdA}}$ & $680.0^{\mathrm{bA}}$ \\
T. atroviride & 6625 & $1.3^{\mathrm{aB}}$ & $692.0^{\mathrm{deA}}$ & $90.7^{\mathrm{jlB}}$ \\
T. erinaceum & 3881 & $10.0^{\mathrm{aC}}$ & $378.7^{\mathrm{iB}}$ & $875.3^{\mathrm{aA}}$ \\
T. ghanense & 3732 & $1.7^{\mathrm{aC}}$ & $766.3^{\mathrm{cdA}}$ & $298.0^{\mathrm{fghB}}$ \\
T. hamatum & 3476 & $1.0^{\mathrm{aC}}$ & $593.3^{\mathrm{efgA}}$ & $92.7^{\mathrm{jlB}}$ \\
T. harzianum & 2842 & $2.3^{\mathrm{aC}}$ & $924.0^{\mathrm{bA}}$ & $176.0^{\mathrm{hijB}}$ \\
T. harzianum & 3935 & $1.3^{\mathrm{aC}}$ & $480.0^{\mathrm{ghiA}}$ & $143.3^{\mathrm{ijB}}$ \\
T. harzianum & 4328 & $2.7^{\mathrm{aB}}$ & $378.0^{\mathrm{iA}}$ & $442.7^{\mathrm{deA}}$ \\
T. harzianum & 4463 & $1.7^{\mathrm{aC}}$ & $758.7^{\mathrm{cdA}}$ & $232.0^{\mathrm{ghiB}}$ \\
T. harzianum & 5482 & $2.7^{\mathrm{aC}}$ & $631.3^{\mathrm{defA}}$ & $369.3^{\mathrm{defB}}$ \\
T. harzianum & 6668 & $3.0^{\mathrm{aB}}$ & $440.0^{\mathrm{hiA}}$ & $0.0^{\mathrm{B}}$ \\
T. koningiopsis & 3880 & $7.7^{\mathrm{aC}}$ & $645.3^{\mathrm{defA}}$ & $146.0^{\mathrm{ijB}}$ \\
T. virens & 4996 & $15.7^{\mathrm{aC}}$ & $844.0^{\mathrm{bcA}}$ & $329.3^{\mathrm{efgB}}$ \\
T. virens & 5629 & $1.7^{\mathrm{aC}}$ & $612.7^{\mathrm{efgA}}$ & $500.0^{\mathrm{cdB}}$ \\
\hline
\end{tabular}

Averages values followed by the same superscript letters, lower case (within column) and capital (within row), do not differ by Tukey test at $5 \%$ probability.

In contrast, according to the data obtained in the present study, the strains $T$. asperelloides URM 3086, URM 3934 and URM 5007; T. asperellum URM 6656; T. hamatum URM 4722; T. koningiopsis URM 3606; and T. virens URM 4466 were not efficient in decolourising Indigo Carmine. These results were due to the fact strains belonging to these species require more time to be adapted on the polluted environment to become able to decolourise the effluent. Gajera et al. [34] obtained similar results 
when assessed the dye decolourisation capability of T. viride and T. harzanium strains isolated from contaminated rhizosphere with an industrial textile effluent in India. In this case, strains belonging to both species required a period longer than 12 days to decolourise completely reactive azo dyes, such as Red HE7B, Violet Reactive 5, Black Red-B, Dark Blue and Light Blue H2GP HEG.

\subsection{Activity of Oxidase Enzymes}

Fungal strains that presented decolourisation percentages of textile dye Indigo Carmine above $70 \%$ were selected for assessment of Lac, LiP and MnP activities (18 strains, Table 3). Based on the data obtained for Lac, LiP and MnP activities and after statistical analysis of averages, a significant difference between the means of LiP and MnP activities was observed (Table 3). In addition, the interaction among the averages of $\mathrm{Lac}, \mathrm{LiP}$ and $\mathrm{MnP}$ indicated that all of the assessed fungal strains were better producers of LiP than the other two enzymes (Lac and MnP) (Table 3).

In a previous study performed by Adnan et al. [14], T. atroviride showed no activity for LiP and $\mathrm{MnP}$. In contrast, in the present study, it was observed that the best LiP activity was obtained for the assays performed with T. atroviride URM 3735 , which presented a production of $1307.0 \mathrm{U} \cdot \mathrm{L}^{-1}$, followed by T. harzianum URM 2842 with an activity of $924.0 \mathrm{U} \cdot \mathrm{L}^{-1}$ and T. virens URM 4996 with an activity of 844.0 U. $\mathrm{L}^{-1}$. In addition, herein, it was observed that for the MnP, the highest activity was obtained for the strain T. erinaceum URM $3881\left(875.3 \mathrm{U} \cdot \mathrm{L}^{-1}\right)$, followed by T. atroviride URM 4950 and URM 3735, $680.0 \mathrm{U} \cdot \mathrm{L}^{-1}$ and $617.3 \mathrm{U} \cdot \mathrm{L}^{-1}$, respectively.

No significant difference between the averages of Lac activity was observed. However, the strain T. virens URM 4996 presented a Lac activity of $15.7 \mathrm{U} \cdot \mathrm{L}^{-1}$ which is numerically greater than those observed for the other species assessed (Table 3). In a previous study, Adnan et al. [14] observed a Lac activity of $5.8 \mathrm{U} \cdot \mathrm{mL}^{-1}$ after four days of experiment for a T. atroviride strain. Authors attested that Lac production was directly related to the degradation of textile dye Reactive Black 5 . In the present work, the Lac production by the four fungal strains belonging to the species T. atroviride (URM 3270, 3735, 4950 and 3881) was assessed. After eight days of the experiment, Lac activities assessed were 1.3, 2.0, 8.3 and $2.3 \mathrm{U} \cdot \mathrm{L}^{-1}$, respectively (Table 3).

Overall, based on the results obtained herein for activities of Lac, LiP and MnP, the following six strains were selected as the best producer of these oxidases and then used in the screening assays of effluent decolourisation: Trichoderma asperellum URM 4926, T. atroviride URM 3735, URM 4950, T. erinaceum URM 3881, T. harzianum URM 2842 and T. virens 4996 (Table 3).

\subsection{Treatment of Real Textile Effluent}

The six above mentioned Trichoderma strains, which were the best enzymatic producers were then selected to decolourise real textile effluent which is characterised by high organic load since the $\mathrm{COD}$ and BOD parameters are higher than the normal accepted for inland surface water disposal $\left(\mathrm{COD}<250 \mathrm{mg} \cdot \mathrm{L}^{-1}\right.$ and BOD $\left.<30 \mathrm{mg} \cdot \mathrm{L}^{-1}\right)$ (Table 4$)$.

Table 4. Physical-chemical analyses of the effluent obtained from the textile manufacture located at the municipality of Toritama, Pernambuco, Brazil.

\begin{tabular}{cccccc}
\hline $\begin{array}{c}\mathrm{COD} \\
\left(\mathrm{mg} \mathrm{O}_{\mathbf{2}} \cdot \mathbf{L}^{-\mathbf{1}}\right)\end{array}$ & $\begin{array}{c}\text { BOD } \\
\left(\mathrm{mg} \mathrm{O}_{\mathbf{2}} \cdot \mathbf{L}^{-\mathbf{1}}\right)\end{array}$ & $\begin{array}{c}\text { Colour } \\
(\mathbf{H A Z E N})\end{array}$ & $\begin{array}{c}\text { Turbidity } \\
(\mathbf{N T U})\end{array}$ & $\mathbf{p H}$ & ${\mathrm{SD}\left(\mathbf{m L}^{-\mathbf{L}^{-1}}\right)}$ \\
\hline 3192.5 & 54.1 & 448.0 & 0.19 & 5.11 & 7.0 \\
\hline
\end{tabular}

Based on the data obtained for: (1) textile effluent; (2) textile effluent supplemented with $0.5 \%$ $(w / v)$ wheat bran; and (3) textile effluent supplemented with $0.05 \%(w / v)$ extract yeast, for each strain, and after statistical analysis of averages, a significant difference between the means was observed (Figure 4). According to the results obtained, T. atroviride URM 4950, T. erinaceum URM 3881 and T. virens URM 4996 showed the best performance in decolourising of textile effluent $(84.6 \%, 36.1 \%$ and 
61.3\%, respectively). In addition, T. asperellum URM 4926 (84.6\%), T. erinaceum URM 3881(66\%) and T. harzianum URM 2842 (60.6\%) presented a good performance of decolourisation when textile effluent supplemented with extract yeast was used.

When the effluent was supplemented with wheat bran, the percentage of effluent decolourisation was higher for the strains T. atroviride URM 3735 (43.0\%), T. erinaceum URM 3881 (35.6\%) and T. virens URM 4996 (23.8\%) (Figure 4).

According to Saravanakumar and Kathiresan [17], a large decolourisation rate (89\%) of Malachite Green dye after 10 days of incubation of T. harzianum TSK8 (JQ809340) was observed when this strain was grown in supplemented medium with $5.8 \mathrm{mg} \cdot \mathrm{L}^{-1}$ yeast extract. In addition, Adnan et al. [14] evaluated the effect of different sources of carbon and nitrogen in the decolourisation of textile dye Reactive Black 5 by T. atroviride. Authors observed that yeast extract was a good source of nitrogen for growth T. atroviride and to stimulate it to decolourise Reactive Black 5 up to $91.1 \%$. Furthermore, authors evaluated dye decolourisation by using ammonium nitrate and ammonium chloride and, in contrast, observed only a decolourisation rate of $29.1 \%$ and $71.7 \%$, respectively.

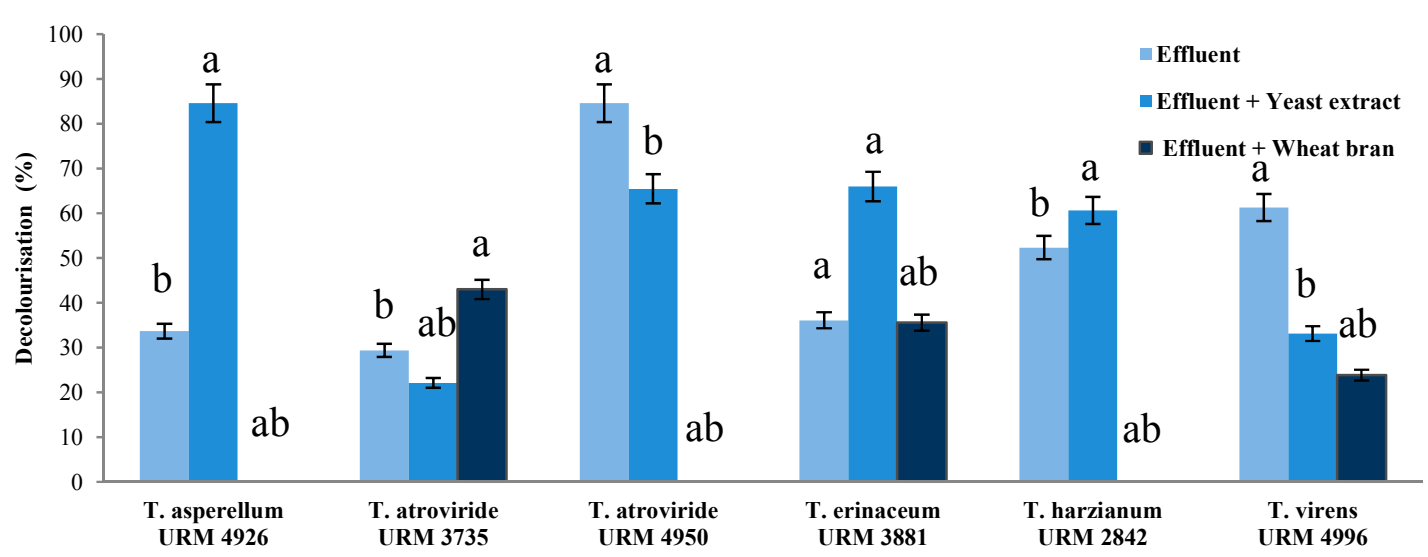

Figure 4. Decolourisation percentage of real textile effluent by the six Trichoderma strains best oxidases producers. Averages followed by the same letters do not differ by Friedman test at $5 \%$ probability.

\section{Conclusions}

The Brazilian Trichoderma asset preserved at the Micoteca URM culture collection was re-identified and made available in the culture collection e-catalogue to be further explored from the biotechnologically point of view. In the specific case of dye decolourisation screening using real textile effluent, the strain T. atroviride URM 4950 gave the best results and can be considered in a scale-up process at industrial level. This strain is herein indicated to be used as a major target for future studies related with the treatment of industrial textile effluent and bioremediation of environments contaminated with dyes. Overall, the data obtained suggest that the dye decolourisation in real textile effluent is not a one-step process. More than one oxidative enzyme can be involved in this complex process. The contribution of these enzymes for decolourisation of textile effluent differs from fungus to fungus. The potential of Trichoderma strains in decolourising real textile dye present in textile effluent and the production of the oxidative enzymes $\mathrm{Lac}, \mathrm{LiP}$ and $\mathrm{MnP}$ were successfully demonstrated. Finally, in this study, the strains available through Micoteca URM culture collection are identified according the current state-of-the-art and better characterised to underpinning life sciences and biotechnology.

Acknowledgments: Authors are grateful to the Fundação de Amparo à Ciência e Tecnologia do Estado de Pernambuco (FACEPE), Brazil for the financial support. C. Santos thanks to the Universidad de La Frontera (Temuco, Chile) for the internal support to the current external funded project (DIUFRO PIA16-0009).

Author Contributions: Keila A. Moreira and Cristina M. Souza-Motta conceived and designed the experiments; Dianny Silva Lisboa and Renan N. Barbosa performed the experiments; Dianny Silva Lisboa, Laura M. Paiva, 
Oliane Magalhães, Keila A. Moreira, Cristina M. Souza-Motta, Cledir Santos and Nelson Lima analysed the data; Keila A. Moreira and Cristina M. Souza-Motta contributed reagents and materials; and Dianny Silva Lisboa, Cledir Santos and Nelson Lima wrote the paper.

Conflicts of Interest: The authors declare no conflict of interest. The founding sponsors had no role in the design of the study; in the collection, analyses, or interpretation of data; in the writing of the manuscript, and in the decision to publish the results.

\section{References}

1. Durruty, I.; Fasce, I.; González, J.F.; Wolski, E.A. A kinetic study of textile dyeing wastewater degradation by Penicillium chrysogenum. Bioprocess Biosyst. Eng. 2015, 38, 1019-1031. [CrossRef] [PubMed]

2. Ottoni, C.A.; Santos, C.; Kozakiewicz, Z.; Lima, N. White-rot fungi capable of decolourising textile dyes under alkaline conditions. Folia Microbiol. 2013, 58, 187-193. [CrossRef] [PubMed]

3. Saroj, S.; Dubey, S.; Agarwal, P.; Prasad, R.; Singh, R.P. Evaluation of the efficacy of a fungal consortium for degradation of azo dyes and simulated textile dye effluents. Sustain. Water Resour. Manag. 2015, 1, $233-243$. [CrossRef]

4. Kanayama, N.; Suzuki, T.; Kawap, K. Purification and Characterization of an Alkaline Manganese Peroxidase from Aspergillus terreus LD-1. J. Biosci Bioeng. 2002, 93, 405-410. [CrossRef]

5. Saparrat, M.C.M.; Martínez, M.J.; Cabello, M.N.; Arambarri, A.M. Screening for ligninolytic enzymes in autochthonous fungal strains from Argentina isolated from different substrata. Rev. Iberoam. Micol. 2002, 19, 181-185. [PubMed]

6. Bonugli-Santos, R.C.; Durranta, L.R.; Silva, M.; Settec, L.D. Production of laccase, manganese peroxidase and lignin peroxidase by Brazilian marine-derived fungi. Enzyme Microb. Technol. 2010, 46, 32-37. [CrossRef]

7. Maciel, M.; Ottoni, C.; Santos, C.; Lima, N.; Moreira, K.; Souza-Motta, C. Production of polygalacturonases by Aspergillus section Nigri strains in a fixed bed reactor. Molecules 2013, 18, 1660-1671. [CrossRef] [PubMed]

8. Maciel, M.D.H.C.; Ottoni, C.A.; Herculano, P.N.; Porto, T.S.; Porto, A.L.F.; Santos, C.; Lima, N.; Moreira, K.A.; Souza-Motta, C.M. Purification of polygalacturonases produced by Aspergillus niger using an aqueous two-phase system. Fluid Phase Equilibr. 2014, 371, 125-130. [CrossRef]

9. Ottoni, C.A.; Lima, L.; Santos, C.; Lima, N. Effect of Different Carbon Sources on Decolourisation of an Industrial Textile Dye Under Alkaline-Saline Conditions. Curr. Microbiol. 2014, 68, 53-58. [CrossRef] [PubMed]

10. Passarini, M.R.Z.; Santos, C.; Lima, N.; Berlinck, R.G.S.; Sette, L.D. Filamentous fungi from the Atlantic marine sponge Dragmacidon reticulatum. Arch. Microbiol. 2013, 195, 99-111. [CrossRef] [PubMed]

11. Sarayu, K.; Sandhya, S. Current technologies for biological treatment of textile wastewater: A review. Appl. Biochem. Biotechnol. 2012, 167, 645-661. [CrossRef] [PubMed]

12. Ottoni, C.; Simões, M.F.; Fernandes, S.; Santos, C.R.; Lima, N. High laccase expression by Trametes versicolor in a simulated textile effluent with different carbon sources and pHs. Int. J. Environ. Res. Public Health 2016, 13, 778. [CrossRef] [PubMed]

13. Zucca, P.; Neves, C.M.B.; Simões, M.M.Q.; Neves, M.G.P.M.S.; Cocco, G.; Sanjust, E. Immobilized lignin peroxidase-like metalloporphyrins as reusable catalysts in oxidative bleaching of industrial dyes. Molecules 2016, 21, 964. [CrossRef] [PubMed]

14. Adnan, L.A.; Sathishkumar, P.; Yusoff, A.R.M.; Hadibarata, T. Metabolites characterization of laccase mediated Reactive Black 5 biodegradation by fast growing ascomycete fungus Trichoderma atroviride F03. Int. Biodeterior. Biodegradation 2015, 104, 274-282. [CrossRef]

15. Hoyos-Carvajal, L.; Orduz, S.; Bissett, J. Genetic and metabolic diversity of Trichoderma from Colombia and adjacent neotropic regions. Fungal. Genet. Biol. 2009, 46, 615-631. [CrossRef] [PubMed]

16. Nicolás, C.; Hermosa, R.; Rubio, B.; Mukherjee, P.K.; Monteb, E. Trichoderma genes in plants for stress tolerance-status and prospects. Plant. Sci. 2014, 228, 71-78. [CrossRef] [PubMed]

17. Saravanakumar, K.; Kathiresan, K. Bioremoval of the synthetic dye malachite green by marine Trichoderma sp. SpringerPlus 2014, 3, 1-12. [CrossRef] [PubMed]

18. Tripathi, P.; Singh, P.C.; Mishra, A.; Chauhan, P.S.; Dwivedi, S.; Bais, R.T.; Tripathi, R.D. Trichoderma: A potential bioremediator for environmental clean up. Clean Techn. Environ. Policy 2013, 15, 541-550. [CrossRef] 
19. Samuels, G.J.; Chaverri, P.; Farr, D.F.; McCray, E.B. Trichoderma Online, Systematic Mycology and Microbiology Laboratory, ARS, USDA. Available online: http://nt.ars-grin.gov/taxadescriptions/keys / TrichodermaIndex.cfm (accessed on 18 February 2016).

20. Santos, C.; Ventura, J.A.; Costa, H.; Fernandes, P.M.B.; Lima, N. MALDI-TOF MS to identify the pineapple pathogen Fusarium guttiforme and its antagonist Trichoderma asperellum on decayed pineapple. Trop. Plant Pathol. 2015, 40, 227-232. [CrossRef]

21. Griffiths, R.I.; Whiteley, A.S.; O'donnell, A.G.; Bailey, M.J. Rapid method for coextraction of DNA and RNA from natural environments for analysis of ribosomal DNA and RRNA-based microbial community composition. Appl. Environ. Microbiol. 2000, 66, 5488-5491. [CrossRef] [PubMed]

22. Samuels, G.J.; Dodd, S.L.; Gams, W.; Castlebury, L.A.; Petrini, O. Trichoderma species associated with the green mold epidemic of commercially grown Agaricus bisporus. Mycologia 2002, 94, 146-170. [CrossRef] [PubMed]

23. Carbone, I.; Kohn, L.M. A method for designing primer sets for speciation studies in filamentous ascomycetes. Mycologia 1999, 91, 553-556. [CrossRef]

24. White, T.J. PCR Protocols, A Guide to Methods and Applications; Academic Press: New York, NY, USA, 1990; pp. 315-322.

25. Tamura, K.; Peterson, D.; Peterson, N.; Stecher, G.; Nei, M.; Kumar, S. MEGA5: Molecular evolutionary genetics analysisusing maximum likelihood, evolutionary distance, and maximum parsimony method. Mol. Biol. Evol. 2011, 28, 2731-2739. [CrossRef] [PubMed]

26. Rice, E.W.; Baird, R.B.; Eaton, A.D.; Clesceri, L.S. Standard Methods for the Examination of Water and Wastewater, 22nd ed.; American Public Health Association: Washington, DC, USA, 2012.

27. Miranda, R.C.M.; Gomes, E.B.; Pereira, J.N.; Marin-Morales, M.A.; Machado, K.M.G.; Gusmão, N.B. Treatment of textile effluent under static bioreactor by Curvularia lunata URM 6179 and Phanerochaete chrysosporium URM 6181. Bioresour. Technol. 2013, 142, 361-367. [CrossRef] [PubMed]

28. Silva, F.A.Z.; Azevedo, C.A.V. Principal Components Analysis in the Software Assistat-Statistical Attendance. In World Congress on Computers in Agriculture, 7; American Society of Agricultural and Biological Engineers: Reno, NV, USA, 2009.

29. Arora, D.S.; Gill, P.K. Comparison of two assay procedures for lignin peroxidase. Enzyme Microb. Technol. 2001, 28, 602-605. [CrossRef]

30. Kuwahara, M.; Glenn, J.K.; Morgan, M.A.; Gold, M.H. Separation and characterization of two extracellular H2O2-dependent oxidases from ligninolytic cultures of Phanerochaete chrysosporium. FEBS Lett. 1984, 169, 247-250. [CrossRef]

31. Silva, F.C.; Chalfoun, S.M.; Batista, L.R.; Santos, C.; Lima, N. Use of a polyphasic approach including MALDI-TOF MS for identification of Aspergillus section Flavi strains isolated from food commodities in Brazil. Ann. Microbiol. 2015, 65, 2119-2129. [CrossRef]

32. Rodrigues, P.; Santos, C.; Venâncio, A.; Lima, N. Species identification of Aspergillus section Flavi isolates from Portuguese almonds using phenotypic, including MALDI-TOF ICMS, and molecular approaches. J. Appl. Microbiol. 2011, 111, 877-892. [CrossRef] [PubMed]

33. Oliveira, M.M.E.; Santos, C.; Sampaio, P.; Romeo, O.; Almeida-Paes, R.; Pais, C.; Lima, N.; Zancope-Oliveira, R.M. Development and optimization of a new MALDI-TOF protocol for identification of the Sporothrix species complex. Res. Microbiol. 2015, 166, 102-110. [CrossRef] [PubMed]

34. Gajera, H.P.; Bambharolia, R.P.; Hirpara, D.G.; Patel, S.V.; Golakiya, B.A. Molecular identification and characterization of novel Hypocrea koningii associated with azo dyes decolourisation and biodegradation of textile dye effluents. Process Saf. Environ. 2015, 98, 406-416. [CrossRef]

(C) 2017 by the authors. Licensee MDPI, Basel, Switzerland. This article is an open access article distributed under the terms and conditions of the Creative Commons Attribution (CC BY) license (http:/ / creativecommons.org/licenses/by/4.0/). 